Research Article,

\title{
"Effect of Secondary Cognitive and Motor Tasks on Selected Gait Parameters in Different Age Groups"
}

\section{Raee Saeed Alqhtani ${ }^{1}$, Adel Alshahrani ${ }^{2}$, Mohammad Abdul Rehman Jarrar ${ }^{3}$, Reyaz Ahmed ${ }^{4}$, Hashim Ahmed ${ }^{1}$ *}

${ }^{1}$ Assistant professor, Department of physiotherapy, College of Applied Medical Sciences, Najran University, Najran, 1988 Saudi Arabia

${ }^{2}$ Associate professor, Department of physiotherapy, College of Applied Medical Sciences, Najran

University, Najran, 1988 Saudi Arabia

${ }^{3}$ Lecturer, Department of physiotherapy, College of Applied Medical Sciences, Najran University, Najran, 1988 Saudi Arabia

${ }^{4}$ Clinical physiotherapist, Department of physiotherapy, College of Applied Medical Sciences, Najran University, Najran, 1988 Saudi Arabia

Email Address: hahasan@nu.edu.sa

\begin{abstract}
:
Since walking is a dynamic activity which is an automatic process and attention demanding task. Dual task while walking may cause changes in gait, therefore this study primarily aims to identify whether a secondary cognitive or motor task would have a greater effect on gait parameters in different age groups. Secondarily, it aims to examine difference in gait performance between young and older adults while performing cognitive and motor tasks. Student's t- test and repeated measure analysis of variance was used for Statistical analyses. Older group had significantly higher gait time (mean difference: 2.61, 3.86, and 6.37seconds), lower stride length (mean difference: $0.26,0.25$, and $0.28 \mathrm{~cm}$ ), and higher step width (mean difference: $1.46,1.85$, and $3.13 \mathrm{~cm}$ ) during simple walking task, motor task and cognitive task while walking, respectively as compared to young adults. This study concludes that the secondary cognitive task has affect the selected gait parameters more in young and older adults as compared to secondary motor task. Additionally, dual task performance has shown difference between gait of young and older adults
\end{abstract}

Keywords: Aging; Balance; Cognitive task; fall; Dual task; Gait; Motor task.

\section{Introduction:}

Dual task is important activity of daily living and most beneficial during walking as it helps to improve communication, transportation, and monitoring of environmental threats to balance and risk of fall can be avoided [1]. Dual task is often known as "concurrent task" comprised of a primary and a secondary task performed simultaneously [1]. Dual task during walking cause changes in gait parameters due to competing demands for limited attentional resources which indicates that walking is an automatic process as well as an attention demanding task [2]. Walking while having conversation on the mobile phone or while observing around obstacles represent examples for the concurrent performance of a motor task (i.e., walking) and a cognitive interference task (e.g., talking). There is a plenty of literatures available that indicates gait pattern gets affected during dual-task walking [2-5]. Dual task may interfere with gait if the capacity of central resources exceeds or it is unable to adequately adapt distribution of attention between two tasks which results in a reduced performance in one or both tasks [2,6-8].

Walking is more demanding and attention taking task in older adults than young adults [6]. Therefore, for older adults, a dual task situation such as walking along with an attention-demanding task cause a division in the attention [9]. Previous 
studies have shown that older adults have more fall risk if they took more time in performing dual tasks including motor and mobility tasks or if they stop walking for a conversation. [10,11] Cognitive processing is paramount for completing motor performance. The performance of a motor skill requires a series of cognitive processes including identification of stimulus, selection of a response, and a retrieval of schema from past long-term memory [12]. Attention is one of the cognitive factors that may affect motor performance. The effect of concurrent tasks on motor performance results in changes in performance if the attention demand is divided between the primary motor task and an additional cognitive or motor task [12].

It has been suggested that the performance of dual task activities cause more interference if both the task require same cognitive processing [13]. For example, Beauchet et al. [13] showed changes in gait parameters during dual task activities including walking and simultaneously performing cognitive task such as counting backwards and a verbal fluency task in older adults and they found significant differences in walking time and cadence under dual task conditions as compared to walking alone. Additionally, Chen et al. [14] reported significantly increased risk of obstacle contact in both young and older adults if their attention was divided. They also found that division of attention caused reduced obstacle avoidance abilities in older adults significantly more than young adults [14]. Similarly, Hollman et al. [15] also showed that older adults have increased variability of stride velocity in dual task when compared with young adults.

There are numerous situations in which dual tasking is used in therapy, however, there is no consensus regarding what kind of dual task to train in order to have the most effective outcomes. The severity of secondary task interference may be an important indicator of the functional condition of the motor system as this will help us to judge the difference in cognitive and motor task according to age group in rehabilitation training programme and may also help us to gain a better understanding of specific associations between gait parameters and executive components, and the related neural correlates, with an ultimate aim of identifying key targets for therapy.

Therefore, this study primarily aims to identify whether a secondary cognitive or motor task would have a greater effect on the spatial and temporal gait variables in different age groups. Secondarily, it aims to examine the difference in gait performance between young and older adults while performing cognitive or motor tasks.

Table1. Demographic details of the participants

\begin{tabular}{|l|l|l|l|}
\hline Variables & $\begin{array}{l}\text { Older Adults } \\
\text { Mean (SD) }\end{array}$ & $\begin{array}{l}\text { Young Adults } \\
\text { Mean (SD) }\end{array}$ & p-value \\
\hline Age, years & $61.28(3.831)$ & $24.80(2.141)$ & $0.001^{*}$ \\
\hline Weight, kg & $64.76(7.870)$ & $61.60(9.504)$ & 0.207 \\
\hline Height, m & $1.62(0.074)$ & $1.62(0.072)$ & 0.849 \\
\hline BMI, kg/m $\mathbf{m}^{2}$ & $24-43(2.351)$ & $23.30(2.729)$ & 0.124 \\
\hline
\end{tabular}

*Statistically significant at $p<0.01$; SD, Standard
deviation; BMI, body mass index

\section{Subjects and Methods:}

\subsection{Participants}

A sample of fifty adults in two groups [Group-I Older adults $(\mathrm{n}=25)$ mean age $61.28 \pm 3.83$, Group-II Young adults $(n=25) 24.80 \pm 2.14]$ were recruited from the Physiotherapy department, Najran University, Saudi Arabia. Study objectives and procedure were properly explained, and a written informed consent was obtained at the beginning of study. All the participants were assigned into two equal groups I and II. To be included in group 1 all subjects should be of age 55- 70 years while for group 2 subjects should be of age 20-30 years, able to follow commands, able to walk over level surface, able to walk independently, have good mental condition as per the Mini-Mental State Exam (score >24). Subjects were excluded if they had any orthopaedic disorders or neurological disorders affecting gait or had 2 or more falls in the last one year.

\subsection{Instruments and Procedure}

\subsubsection{Instruments}

Instruments and tools used were paper walkway, stopwatch, standard measuring tape, markers, paint and brush, socks, disposable plastic bags, chairs, 12 wooden square blocks, ruler, weighing machine, height rod, ball, and apron.

\subsubsection{Procedure}

The subjects participated for the study were given a detailed explanation of the procedure at the beginning of the study. A visual demonstration of walking test was given under three different conditions. Subjects were asked to walk with their comfortable speed for $10 \mathrm{~m}$ on a paper walkway 
(10 x 0.5 meters). Following this, the subjects were prepared for the second task in which they were asked to wear an apron with two pockets in front of it and the dominant hand was identified by asking the subject to catch the ball. The subjects were then asked to transfer wooden blocks from one pocket to another, one at a time starting from the dominating side while walking. In the third task, they were asked to count backwards starting from fifty. The subjects were reminded to maintain their speed while walking. These tasks were given in the randomized order. A trail session was given for familiarization.

Colour paint method was used in the study in which the subjects were asked to wear disposable plastic bags followed by socks and paint was applied with the help of brush to the sole and impression of footprints were taken. These footprints were used for computing the four gait variables. The gait variables including time, steps, stride length, and step width were noted. The initial (e.g., acceleration phase) and final distance (e.g., deceleration phase) of 1.5 meters were excluded in the data analysis.

\section{Statistical analyses:}

Data analyses was conducted using SPSS window version 22. A student's t- test was used to analyze difference between the performance of young and older adults. Repeated measure analysis of variance was used to analyze intra group variations in walking time, cadence, stride length, and step width during simple walking, performing block transference task while walking, and arithmetic task while walking. The significance level was fixed at $\mathrm{p} \leq 0.01$.

Table2: Within group comparisons of gait parameters during simple walking, motor task while walking, and cognitive task while walking

\begin{tabular}{|c|c|c|c|c|c|c|c|c|c|}
\hline \multirow[t]{2}{*}{ Groups } & \multirow[t]{2}{*}{ Variables } & \multirow{2}{*}{$\begin{array}{l}\text { Simple } \\
\text { walking } \\
(\mathrm{SW})\end{array}$} & \multirow{2}{*}{$\begin{array}{l}\text { Motor } \\
\text { task } \\
(\mathrm{MT})\end{array}$} & \multirow{2}{*}{$\begin{array}{l}\text { Cognitive } \\
\text { task (CT) }\end{array}$} & \multicolumn{2}{|c|}{ ANOVA } & \multicolumn{3}{|c|}{ Post hoc analysis (Bonferroni test) } \\
\hline & & & & & $\mathrm{F}$ & $\mathrm{P}$ & $\begin{array}{l}\text { SW versus } \\
\text { MT }\end{array}$ & $\begin{array}{l}\text { SW versus } \\
\text { CT }\end{array}$ & $\begin{array}{l}\text { MT versus } \\
\text { CT }\end{array}$ \\
\hline \multirow[t]{4}{*}{$\begin{array}{l}\text { Old } \\
\text { adults }\end{array}$} & Time & $10.72 \pm 2.45$ & $\begin{array}{l}12.66 \pm \\
2.94\end{array}$ & $\begin{array}{l}15.84 \pm \\
3.38 \\
\end{array}$ & 70.83 & $0.001 *$ & $\mathrm{~d}=-1.94^{*}$ & $\mathrm{~d}=-5.12 *$ & $\mathrm{~d}=-3.18^{*}$ \\
\hline & Steps & $18.40 \pm 1.68$ & $\begin{array}{l}19.76 \pm \\
1.73\end{array}$ & $\begin{array}{l}20.88 \pm \\
1.85\end{array}$ & 193.87 & $0.001 *$ & $\mathrm{~d}=-1.36^{*}$ & $\mathrm{~d}=-2.48^{*}$ & $\mathrm{~d}=-1.12^{*}$ \\
\hline & $\begin{array}{l}\text { Stride } \\
\text { length }\end{array}$ & $1.19 \pm 0.14$ & $\begin{array}{l}1.18 \pm \\
0.13 \\
\end{array}$ & $1.13 \pm 0.14$ & 20.87 & $0.001 *$ & $\mathrm{~d}=0.01$ & $\mathrm{~d}=0.06^{*}$ & $\mathrm{~d}=0.05^{*}$ \\
\hline & Step width & $10.47 \pm 1.39$ & $\begin{array}{l}11.02 \pm \\
1.45\end{array}$ & $\begin{array}{l}12.47 \pm \\
2.25\end{array}$ & 25.16 & $0.001 *$ & $\mathrm{~d}=0.54 *$ & $\mathrm{~d}=-2.10^{*}$ & $\mathrm{~d}=-1.45^{*}$ \\
\hline \multirow[t]{4}{*}{$\begin{array}{l}\text { Young } \\
\text { adults }\end{array}$} & Time & $8.11 \pm 0.84$ & $\begin{array}{l}8.80 \pm \\
1.17\end{array}$ & $9.47 \pm 1.22$ & 61.55 & $0.001 *$ & $\mathrm{~d}=-0.69^{*}$ & $\mathrm{~d}=-1.36^{*}$ & $\mathrm{~d}=-0.67 *$ \\
\hline & Steps & $17.76 \pm 1.20$ & $\begin{array}{l}17.84 \pm \\
1.24\end{array}$ & $\begin{array}{l}18.56 \pm \\
1.22\end{array}$ & 37.02 & $0.001 *$ & $\mathrm{~d}=-0.08$ & $\mathrm{~d}=-0.80^{*}$ & $\mathrm{~d}=-0.72 *$ \\
\hline & $\begin{array}{l}\text { Stride } \\
\text { length }\end{array}$ & $1.45 \pm 0.09$ & $\begin{array}{l}1.43 \pm \\
0.08\end{array}$ & $1.41 \pm 0.09$ & 121.70 & $0.001 *$ & $\mathrm{~d}=0.02^{*}$ & $\mathrm{~d}=0.04^{*}$ & $\mathrm{~d}=0.02 *$ \\
\hline & Step width & $9.01 \pm 1.33$ & $\begin{array}{l}9.17 \pm \\
1.36\end{array}$ & $9.34 \pm 1.29$ & 13.43 & $0.001 *$ & $\mathrm{~d}=-0.16^{*}$ & $\mathrm{~d}=-0.33^{*}$ & $\mathrm{~d}=-0.17 *$ \\
\hline
\end{tabular}

$\mathrm{d}=$ mean difference; *statistically significant at $\mathbf{p}<0.01$.

\section{Results:}

There was no significant difference in demographics except age between older and young adults as shown in table 1 . There were statistically significant differences in walking time, cadence, stride length, and step width between simple walking and performing block transference task while walking, or arithmetic task while walking in older and young adults (Table 2). Cognitive task while walking significantly interfere with gait parameters in older and young adults. Table 3 presents comparison of gait parameters during simple walking, motor task while walking, and cognitive task while walking between older and young adults. Older adults had significantly higher gait time (mean difference, 2.61 seconds), lower stride length (mean difference, $0.26 \mathrm{~cm}$ ), and higher step width (mean difference, $1.46 \mathrm{~cm}$ ) during simple walking task as compared to young adults. However, there was no statistically significant difference of cadence (mean difference, $0.64 \mathrm{steps} / \mathrm{min}$ ) between older and young adults during simple walking task. Older adults had significantly higher gait time (mean difference, 
3.86 seconds), higher cadence (mean difference, 1.92 steps/min), lower stride length (mean difference, $0.25 \mathrm{~cm}$ ), and higher step width (mean difference, $1.85 \mathrm{~cm}$ ) during motor task (Block transfer while walking) as compared to young adults. Older adults had significantly higher gait time (mean difference, 6.37 seconds), higher cadence (mean difference, 2.32 steps/min), lower stride length (mean difference, $0.28 \mathrm{~cm}$ ), and higher step width (mean difference, $3.13 \mathrm{~cm}$ ) during cognitive task (Counting backwards while walking) as compared to young adults.

Table3: Between group comparisons of gait parameters between old and young adults

\begin{tabular}{|c|c|c|c|c|c|}
\hline \multirow[b]{2}{*}{ Task } & \multirow[b]{2}{*}{ Variable } & \multirow{2}{*}{$\begin{array}{l}\text { Old adults } \\
\qquad(n=25 \\
\text { Mean } \pm \text { SD }\end{array}$} & \multirow{2}{*}{$\begin{array}{l}\text { Young adults } \\
\quad(n=25) \\
\text { Mean } \pm \text { SD }\end{array}$} & \multicolumn{2}{|l|}{ T test } \\
\hline & & & & $\mathrm{t}$ & $* \mathrm{p}$ \\
\hline \multirow{4}{*}{$\begin{array}{l}\text { Simple } \\
\text { Walking }\end{array}$} & Time & $10.72 \pm 2.45$ & $8.11 \pm 0.84$ & 5.02 & 0.001 \\
\hline & Steps & $18.40 \pm 1.68$ & $17.76 \pm 1.20$ & 1.54 & 0.128 \\
\hline & Stride length & $1.19 \pm 0.14$ & $1.45 \pm 0.09$ & -7.73 & 0.001 \\
\hline & Step width & $10.47 \pm 1.39$ & $9.01 \pm 1.33$ & 3.79 & 0.001 \\
\hline \multirow{4}{*}{$\begin{array}{l}\text { Block transfer while } \\
\text { walking }\end{array}$} & Time & $12.66 \pm 2.94$ & $8.80 \pm 1.17$ & 6.09 & 0.001 \\
\hline & Steps & $19.76 \pm 1.73$ & $17.84 \pm 1.24$ & 4.48 & 0.001 \\
\hline & Stride length & $1.18 \pm 0.13$ & $1.43 \pm 0.08$ & -7.95 & 0.001 \\
\hline & Step width & $11.02 \pm 1.45$ & $9.17 \pm 1.36$ & 4.63 & 0.001 \\
\hline \multirow{4}{*}{$\begin{array}{l}\text { Counting backwards } \\
\text { while walking }\end{array}$} & Time & $15.84 \pm 3.38$ & $9.47 \pm 1.22$ & 8.85 & 0.001 \\
\hline & Steps & $20.88 \pm 1.85$ & $18.56 \pm 1.22$ & 5.21 & 0.001 \\
\hline & Stride length & $1.13 \pm 0.14$ & $1.41 \pm 0.09$ & -8.35 & 0.001 \\
\hline & Step width & $12.47 \pm 2.25$ & $9.34 \pm 1.29$ & 6.00 & 0.001 \\
\hline
\end{tabular}

*Statistically significant at $\mathbf{p}<0.01$.

\section{Discussion:}

The purpose of this study was to identify whether a secondary cognitive or motor task would have a greater effect on the spatial and temporal gait variables in different age groups and also to find out whether there is any difference in gait performance between older and young adults while performing cognitive or motor tasks. The older adults showed higher gait time, cadence, and step width and a lower stride length while walking with a secondary cognitive task or a secondary motor task. While addition of cognitive task may affect gait parameters during walking, a secondary motor task did not interfere walking performance. Beauchet et al. [2,13] reported that the changes in gait parameters during dual task may results from interference between gait and attention dividing task. Since the cerebral capacity of attention demands was shared between gait and attention dividing motor or cognitive task, the dual task interference caused changes in gait parameters. Similarly, the present study found an increased walking time and cadence while performing a secondary task indicates dual task interference.

The older subjects showed greater changes in gait patterns in cognitive task as compared to motor task. As gait control needs more attentional demands along with executive functions in the older adults, it appears that combining a cognitive task (e.g., an arithmetic task) with walking caused increased demands for executive functions in older adults [13]. However, the decline in performance during motor task in older adults could be due to competition for the same cortical structures in performing decrements since same input and output resources are shared [16].

The young adults also showed an increased walking time, cadence, and step width in a secondary cognitive or a secondary motor task as compared to simple walking. A reduction of stride length was also revealed in young adults while walking with secondary cognitive task or secondary motor task as compared to simple walking. Shea et al. [1] carried out a study on Parkinson's disease patients and healthy elderly subjects. They found a reduction in gait speed and 
stride length in both the groups while performing secondary motor or cognitive tasks [1]. Huang et al. [12] carried out a study to identify the effect of concurrent task performance in gait variables in children. These subjects showed difficulty in maintaining motor performance while simultaneously processing cognitive information. They have decreased gait speed and step length. These changes are in the same lines as those found in the present study. It might be due to increased interference effect on walking performance for the task which require a simultaneous sensory processing. Therefore, walking speed and stride length were decreased during secondary tasks to compensate the balance requirement for gait [8].

On inter-group comparison between old and young subjects, significant increases in time taken, number of steps, step width and a decrease in stride length was observed. During simple walking older subjects performed poorly as compared to young subjects. Similar decrement in performance with age was seen while performing a motor task during walking. An additional cognitive task during walking showed that the older subjects have difficulty performing a dual task as compared to young. Several past studies have also reported a reduced walking speed, stride length, step length, and swing phase and increased duration of double support periods [17-19]. Studies have shown that dual task activities cause poor gait and balance function in older adults [8]. Thus, there is a delay in sensory processing and integrations of motor reactions in older adults. Additionally, strength and coordination are reduced, and movements tends to become slower in older adults [20,21]. Moreover, decreased stability in elderly is the cumulative effect of deficits in sensory, motor, and central processing pathways, rather than impairment of

\section{Conclusions:}

This study concludes that the secondary cognitive task has affect the selected gait parameters more in young and older adults as compared to secondary motor task. Additionally, dual task performance has shown difference between gait of young and older adults. More randomized studies are warranted to further validate these results.

\section{Abbreviations:}

SW, Simple walking; MT, Motor task; CT, Cognitive task;

\section{Author contributions:}

RSA. and HA. Conceived and designed the experiments; RA. And MAJ performed the experiments; AS. analyzed the data; RSA. and HA. any one component [22,23]. While healthy older adults can perform an isolated cognitive or motor task, the concurrent performance of one or both may be severely impaired [24].

The current study had some potential limitations. First, the sample size was small. Therefore, more studies are warranted using a large sample size. Second, age of young and old adults was limited to only a small range (e.g., Young age, 20-30 years and old age, 55-70 years). Therefore, it is important to investigate the effect of aging on gait parameters in middle and more advanced age groups. Third, this study is limited to only male population. Therefore, future study should investigate effect of aging on gait parameters and interference of dual tasks in both male and female. Given the importance of dual tasks in everyday life and the numerous groups of people experiencing difficulties while dual tasking; the possibilities of adapting dual tasks in therapy should be a topic of future research.

Clinical implications

The severity of dual task interference between motor and other simultaneous tasks may be an important indicator of the functional condition of the motor system. Many day-to-day activities involve simultaneous performance of motor and cognitive tasks. The performance of a motor task under dual task conditions is better than a single task condition to assess a functional ability. The results of the present study may help identify dual tasks interference in gait performance of older adults. An additional cognitive task results in poorer gait performance when compared to an additional motor task while walking in older subjects, thus indicating that gait training programs should focus on dual task training for efficient gait control.

Wrote the paper. All authors contributed to the final version of the manuscript. All authors read and approved the final manuscript.

\section{Acknowledgements:}

The authors would like to express their Gratitude's to the ministry of education and the deanship of scientific research - Najran University - Kingdom of Saudi Arabia for their support.

\section{Funding:}

Nil

\section{Conflict of interest:}

"The authors declare no conflict of interest." 


\section{References:}

[1] O'Shea S, Morris ME, Iansek R. Dual task interference during gait in people with Parkinson disease: effects of motor versus cognitive secondary tasks. Physical therapy. 2002;82:888-97.

[2] Beauchet O, Dubost V, Herrmann FR, Kressig RW. Stride-to-stride variability while backward counting among healthy young adults. Journal of neuroengineering and rehabilitation. 2005;2:26.

[3] Beurskens R, Bock O. Role of motor skills and visual demand for age-related deficits in dualtask walking. Ageing Research. 2011 Jun 8;2(1):e5-.

[4] Beurskens R, Bock O. Age-related deficits of dual-task walking: a review. Neural plasticity. 2012 Oct;2012.

[5] Kelly VE, Janke AA, Shumway-Cook A. Effects of instructed focus and task difficulty on concurrent walking and cognitive task performance in healthy young adults. Experimental brain research. 2010 Nov 1;207(1-2):65-73.

[6] Woollacott M, Shumway-Cook A. Attention and the control of posture and gait: a review of an emerging area of research. Gait \& posture. 2002; 16:1-4.

[7] Bloem BR, Steijns JA, Smits-Engelsman BC. An update on falls. Current opinion in neurology. 2003; 16:15-26.

[8] Bloem BR, Valkenburg VV, Slabbekoorn M, Willemsen MD. The Multiple Tasks Test: development and normal strategies. Gait \& posture. 2001; 14:191-202.

[9] Verhaeghen P, Cerella J. Aging, executive control, and attention: A review of metaanalyses. Neuroscience \& Biobehavioral Reviews. 2002; 26:849-57.

[10] Schrodt LA, Mercer VS, Giuliani CA, Hartman M. Characteristics of stepping over an obstacle in community dwelling older adults under dual-task conditions. Gait \& posture. 2004;19:279-87.

[11] Lundin-Olsson L, Nyberg L, Gustafson Y. Stops walking when talking as a predictor of falls in elderly people. Lancet. 1997; 349:617.

[12] Huang HJ, Mercer VS, Thorpe DE. Effects of different concurrent cognitive tasks on temporal-distance gait variables in children. Pediatric Physical Therapy. 2003; 15:105-13.
[13] Beauchet O, Dubost V, Aminian K, Gonthier R, Kressig RW. Dual-task-related gait changes in the elderly: does the type of cognitive task matter? Journal of motor behavior. 2005; 37:259.

[14] Chen HC, Schultz AB, Ashton-Miller JA, Giordani B, Alexander NB, Guire KE. Stepping over obstacles: dividing attention impairs performance of old more than young adults. The Journals of Gerontology Series A: Biological Sciences and Medical Sciences. 1996;51:M116-22.

[15] Hollman JH, Salamon KB, Priest AW. Agerelated differences in stride-to-stride variability during dual task walking: a pilot study. Journal of Geriatric Physical Therapy. 2004;27:83.

[16] Weeks DL, Forget R, Mouchnino L, Gravel D, Bourbonnais D. Interaction between attention demanding motor and cognitive tasks and static postural stability. Gerontology. 2003;49:225-32.

[17] Ostrosky KM, VanSwearingen JM, Burdett RG, Gee Z. A comparison of gait characteristics in young and old subjects. Physical therapy. 1994;74:637-44.

[18] Finley FR. Locomotion patterns in elderly women. Arch. Phys. Med. Rehabil.1969;50:140-6.

[19] Levangie PK, Norkin CC. Joint Structure andFunction: A Comprehensive Analysis. 4th ed.Philadelphia, PA, F.A. Davis Company, 2005:517-547.

[20] Spirduso WW, Clifford P. Replication of age and physical activity effects on reaction and movement time. Journal of Gerontology. 1978;33:26-30.

[21] Lewis CB. Geriatric physical therapy: a clinical approach. Prentice Hall; 1994.

[22] Hurley MV, Rees J, Newham DJ. Quadriceps function, proprioceptive acuity and functional performance in healthy young, middle-aged and elderly subjects. Age and ageing. 1998;27:55-62.

[23] Guccione AA, Avers D, Wong R. Geriatric physical therapy-ebook. Elsevier Health Sciences; 2011.

[24] Haggard P, Cockburn J, Cock J, Fordham C, Wade D. Interference between gait and cognitive tasks in a rehabilitating neurological population. Journal of Neurology, Neurosurgery \& Psychiatry. 2000;69:479-86. 